\title{
The use of psychotropic medication during pregnancy: how about the newborn?
}

This article was published in the following Dove Press journal:

Neuropsychiatric Disease and Treatment

28 August 2013

Number of times this article has been viewed

\author{
Noera Kieviet ${ }^{1}$ \\ Koert M Dolman' \\ Adriaan Honig ${ }^{2}$ \\ 'Department of Paediatrics, \\ ${ }^{2}$ Department of Psychiatry, Psychiatry \\ Obstetrics Paediatrics Expert \\ Center, Sint Lucas Andreas Hospital, \\ Amsterdam, The Netherlands
}

\begin{abstract}
Infants are at risk of developing symptoms of Poor Neonatal Adaptation (PNA) after exposure to psychotropic drugs in utero. Such symptoms are largely similar after exposure to antidepressants, antipsychotics and benzodiazepines and consist of mostly mild neurologic, autonomic, respirator and gastro-intestinal abnormalities. Most symptoms develop within 48 hours after birth and last for 2-6 days. After exposure to Selective Serotonin Reuptake Inhibitors (SSRIs), mirtazapine or venlafaxine in utero, breastfeeding is presumably protective for development of PNA. The dosage of antidepressants does not seem to be related to the risk of PNA. In order to objectify possible symptoms of PNA, observation of mother and child at the maternity ward is advisable. If PNA symptoms do not occur, an observation period of 48-72 hours is sufficient. This applies to all types of psychotropic drugs. When PNA symptoms are present it is advisable to observe the infant until the symptoms are fully resolved. Observation can be performed by trained nurses using the Finnegan scoring list. This observation list should be administered every 8 hours. Interpretation of the scores should be carried out by a paediatrician. In most cases symptoms are non-specific. Therefore other diagnoses, such as infection or neurologic problems, have to be excluded. When there is any doubt on possible intoxications during pregnancy, toxicological urine screening is indicated. Most cases of PNA are mild, of short duration and self-limiting without need for treatment. Supporting measures such as frequent small feedings, swaddling and increase of skin to skin contact with the mother is usually sufficient. In case of severe PNA it is advised to admit the infant to the Neonatal Care Unit (NCU). Phenobarbital is a safe therapeutic option. There seem to be no major long term effects; however, additional studies are necessary in order to draw definite conclusions.
\end{abstract}

Keywords: withdrawal, neonatal abstinence, psychiatric disorders, SSRI, antidepressants

\section{Introduction}

For women with a known psychiatric disorder, pregnancy and the first six months after delivery are a vulnerable period, in which psychiatric disorders may relapse or worsen. Of all pregnant women, approximately $15 \%$ have psychiatric problems, in particular depression and anxiety. ${ }^{1,2}$

The possible negative effects of untreated psychiatric symptoms to mother and child have to be weighed against the possible negative effects of psychotropic medication use during pregnancy, in order to diminish maternal and neonatal complications both during and after pregnancy.

Untreated psychiatric disorders during pregnancy may lead to three major complications. Firstly, it can lead to pregnancy complications, such as low birth weight and prematurity, which is partly due to maternal stress related elevated cortisol levels. ${ }^{3-6}$
Correspondence: Noera Kieviet Sint Lucas Andreas Hospital, Psychiatry Obstetrics Paediatrics Expert Center, Jan Tooropstraat 164, I06I AE Amsterdam, The Netherlands

Tel +3I 0205108790

Fax +31 0206853059

Email n.kieviet@slaz.nl 
Secondly, maternal symptoms of depression and anxiety may lead to irritation, agitation, lethargy, and less alertness, as well as poverty of facial expressions in infants. ${ }^{6-8}$ Lastly, maternal psychiatric symptoms can lead to attachment problems between mother and child, which are a risk factor for learning and behavioural problems later in life..$^{9-11}$

The possible risks of psychotropic drug use during pregnancy, such as malformations, pregnancy complications, Poor Neonatal Adaptation (PNA), and long term effects should be carefully weighed against the benefits. In daily practice the use of psychotropic drugs during pregnancy increases gradually. Approximately $3.5 \%$ of all pregnant women in the Western world use psychotropic drugs during pregnancy. ${ }^{12}$

To assist the decision process regarding the treatment of psychiatric disorders during pregnancy many guidelines have been developed and reviews have been written. ${ }^{13-15}$ However, these writings mainly focus on the risk of malformations and do not provide recommendations regarding observation and treatment of PNA. Therefore, this article focuses on PNA in infants exposed to the most commonly used psychotropic drugs in utero; antidepressants, antipsychotics, mood stabilisers and benzodiazepines, and can serve as a guideline for observation of infants exposed to these psychotropic drugs in utero.

\section{Etiology}

Symptoms of PNA are caused by exposure to psychotropic drugs. However, the exact etiology is not fully understood. There are three possible explanations. First of all, symptoms may be caused by withdrawal of psychotropic drugs. In adults, psychotropic drugs, including antidepressants, antipsychotics and benzodiazepines, may result in withdrawal symptoms when not gradually tapered. ${ }^{16,17}$ Since all psychotropic drugs pass the placenta, ${ }^{18-20}$ abrupt discontinuation of drug exposure after birth can lead to symptoms of withdrawal in infants resembling symptoms of withdrawal in adults. Symptoms include feeding difficulties, irritability and tremors. ${ }^{21,22}$ Most symptoms do not develop until eight hours after birth ${ }^{23-25}$ and proceed even though medication exposure has ceased, which is a typical symptom of withdrawal. ${ }^{23,24,26}$ In most cases of withdrawal, plasma concentrations of psychotropic drugs are low..$^{20,22,23,25,27}$

Another cause of the symptoms is drug toxicity ${ }^{28,29}$ which is a known, although rare, phenomenon in adults. Symptoms of drug toxicity are partly similar to symptoms of withdrawal, such as jitteriness and hyperreflexia. However, symptoms of toxicity develop directly after birth. ${ }^{21,22,29}$ In most cases of toxicity, plasma concentrations of psychotropic drugs are high. ${ }^{29-31}$
It can be difficult to distinguish withdrawal of toxicity, since symptoms of withdrawal and toxicity are largely similar. Therefore many investigators postulate that a combination of withdrawal and toxicity is possible. ${ }^{23,24,32-35}$ Since there is no consensus, multiple terms are used, such as poor neonatal adaptation, neonatal behavioural syndrome, postnatal adaptation syndrome/symptoms, transient neonatal symptoms, neonatal effects, neonatal complications, and neonatal abstinence syndrome. ${ }^{22,23,35,36}$ Table 1 presents characteristics of toxicity and withdrawal after exposure to psychotropic drugs in utero.

Furthermore, it has been hypothesized that psychotropic drugs may act as intrauterine stressors. This stress can initiate alterations in fetal programming and development that might produce alterations in the child's behaviour at any age, a phenomenon known in cocaine exposed infants. ${ }^{37}$

Apart from exposure to psychotropic medication in utero, other factors, such as depression and anxiety of the mother, ${ }^{7,8,36-39}$ genetic, epigenetic and environmental factors can also lead to symptoms of restlessness in infants. ${ }^{6,33,35,37,40}$ This multifactorial origin can also explain the variability of PNA symptoms in infants. ${ }^{36,37}$ Thereafter, infants have a limited repertoire of nonspecific activities. This can make it difficult to distinguish PNA from other syndromes such as infection.

Table I Characteristics of toxicity versus withdrawal in infants exposed to psychotropic drugs in utero

\begin{tabular}{lll}
\hline & Toxicity & Withdrawal \\
\hline Onset of symptoms & Immediately post & $8-48$ hours after \\
& partum & birth \\
Medication level of the infant & High & Low \\
Medication half life time & Long & Short \\
Type of psychotropic drug & Antidepressants & Antidepressants \\
& Benzodiazepines & Benzodiazepines \\
& Antipsychotics & Antipsychotics \\
& Lithium & Lamotrigine \\
& Lamotrigine ${ }^{a}$ & \\
& \multicolumn{2}{c}{ Agitation/irritability } \\
Common symptoms & \multicolumn{2}{c}{ Tremors } \\
& \multicolumn{2}{c}{ Myoclonia } \\
& \multicolumn{2}{c}{ Respiratory distress } \\
& Hyperthermia & Feeding difficulties \\
& and sweating & \\
& Hyperreflexia & Vomiting \\
& Diarrhea & Sleeping difficulties \\
& Rigidity & Hypo-and \\
& & hypertonia \\
\hline
\end{tabular}

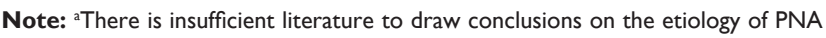
symptoms after exposure to lamotrigine in utero. 


\section{Symptoms}

PNA consists of neurologic, autonomic, respirator, and gastro-intestinal symptoms, which are largely similar after exposure to antidepressants, antipsychotics and benzodiazepines (Table 2). $5,13,16,17,19,21-28,33,35,36,40-64$

In most infants symptoms are mild, such as sleep disturbances. Severe symptoms, such as convulsions, are rare. ${ }^{23,24}$

This review presents a resume of the most recent literature on PNA after exposure to the most commonly used psychotropic drugs in utero.

\section{Selective Serotonin Reuptake Inhibitors}

The use of SSRIs during pregnancy has increased during the last few years, as knowledge has grown of the consequences of such use. Nowadays, $1.8 \%-2.8 \%$ of all pregnant women use an SSRI during pregnancy. ${ }^{24,65-67}$

Of all infants exposed to an SSRI in utero, $20 \%-77 \%$ develop symptoms of PNA, although most studies reported percentages around 30\%. $24,26,27,35,36,42,45,68$ Some studies described an increased incidence of PNA after exposure to paroxetine and fluoxetine compared to other SSRIs, ${ }^{16,23,34,53,69}$ though other studies did not find this association. ${ }^{17,70}$

The half-life of the SSRI seems to influence the risk of withdrawal and toxicity; SSRIs with a short half-life, such as paroxetine, cause more withdrawal, however less toxicity, compared to SSRIs with a long half-life, such as fluoxetine. ${ }^{16,22,23,69,71}$ However, after exposure to SSRIs with a long half-life, withdrawal is more common than toxicity.

Most symptoms develop within 48 hours after birth and last for 2-6 days. ${ }^{24,27,42}$ If PNA symptoms do not occur in the first 48 hours after birth, development of PNA is unlikely. ${ }^{26,45}$

Table 2 Symptoms of PNA in infants exposed to antidepressants, antipsychotics or benzodiazepines in utero

\begin{tabular}{ll}
\hline Common symptom & Less common symptom \\
\hline Neurological & Neurological \\
Jitteriness & Convulsions \\
Muscle tone regulation disorders & Hyperreflexia \\
Tremors & Lethargia \\
Sleeping difficulties & Gastro-intestinal \\
High pitched or frequent crying & Diarrhea \\
Agitation/irritability & Uncoordinated/weak sucking \\
Myoclonia & Vomiting/regurgitation \\
Gastro-intestinal & Autonomus \\
Feeding difficulties & Temperature instability \\
Respiratory & Mottling \\
Respirator distress & Excessive sweating \\
& Nasal stuffiness \\
\hline
\end{tabular}

Abbreviation: PNA, poor neonatal adaptation.
Some studies ${ }^{5,42,72,77}$ showed an increased risk of hypoglycemia and hyperbilirubinemia. However, evidence is limited and there are no published recommendations on whether

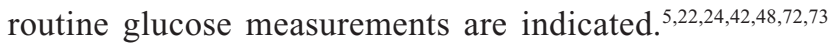
There is conflicting clinical evidence regarding an elevated risk of Persistent Pulmonary Hypertension of the Newborn (PPHN) after exposure to SSRIs. The absolute risk cannot be determined, but is very small, probably less than $1 \%{ }^{74}$ The FDA advises to treat depression during pregnancy as clinically appropriate since there is not sufficient evidence to conclude that SSRI use in pregnancy cause PPHN. Therefore discontinuation, lowering the dose or switching to another type of antidepressant is not recommended..$^{75}$

\section{Tricyclic Antidepressants}

Of all infants exposed to Tricyclic Antidepressants (TCAs) in utero, $20 \%-50 \%$ develops PNA. ${ }^{76}$

Symptoms of PNA after exposure to TCAs are similar to symptoms after exposure to SSRIs (Table 2). ${ }^{13,19,72,77}$ Most symptoms develop within 48 hours of birth and last for 2-6 days. ${ }^{61}$

Apart from PNA, anticholinergic symptoms such as urine retention and obstipation have been described in two case reports. However, these symptoms are rare. ${ }^{19,77,78}$

\section{Other types of antidepressants}

Other allowed and frequently used antidepressants during pregnancy are venlafaxine, a Serotonin Norepinephrine Reuptake Inhibitor (SNRI), bupropion, an atypical antidepressant, and mirtazapine, a Noradrenergic and Specific Serotonergic Antidepressant (NaSSA). After exposure to venlafaxine the risk of PNA seems to be comparable to the risk after exposure to SSRIs. ${ }^{79,80}$ After exposure to mirtazapine PNA is described in one case report. ${ }^{46}$ There are no reports describing PNA after exposure to bupropion. Data on infants exposed to mirtazapine or bupropion without symptoms of PNA are not published.

\section{Antipsychotics}

Antipsychotics are defined as first generation antipsychotics, also called typical antipsychotics and second generation antipsychotics, also called atypical antipsychotics.

Literature on PNA after exposure to first and second generation antipsychotics is limited. However, there is evidence that exposure to both generation antipsychotics can lead to symptoms of PNA (Table 2). ${ }^{19,37,50,58,81,82}$ Numbers on the incidence of PNA after exposure to antipsychotics are lacking. 
Extrapyramidal symptoms, such as increased muscle tone, tremors, hyperactivity, agitation, dystonia, decreased sucking reflex, motor restlessness, abnormal movements and primitive reflexes, can also occur. ${ }^{44,50,58-61,82}$ Most symptoms develop within 48 hours of birth and last for 2-6 days. ${ }^{19,50}$

\section{Mood stabilisers}

Lithium is the most commonly prescribed mood stabiliser during pregnancy. ${ }^{83}$ The most often described syndrome after intrauterine exposure to lithium is the floppy infant syndrome, which develops directly after birth. This syndrome consists of symptoms such as hypotonia, hypothermia, respiratory depression, cyanosis, arrhythmias and decrease sucking reflex. ${ }^{19,57,58,60-62,83-86}$ Although exact figures on incidence are lacking, the incidence is suggested to be low. ${ }^{83}$ Other described lithium related symptoms are neonatal thyroid toxicity, nephrogenic diabetes insipidus, cardiovascular and renal dysfunctions, hyperbilirubinemia, hepatotoxicity and PPHN. These symptoms are generally self-limiting. ${ }^{57,59,60,62,83,86}$ Most symptoms develop within one day and disappear in 2-10 days after birth. ${ }^{62,87}$ However, based on literature and our clinical experience, most infants do not show any symptoms..$^{83,86}$ Some authors advise to monitor lithium serum levels, thyroid levels, urea and electrolytes in the infant ${ }^{84}$ Since symptoms are rare and self-limiting we do not advise routine additional testing.

A higher serum lithium concentration $(>0.64 \mathrm{meq} / \mathrm{liter})$ leads to an increased risk of obstetric and neonatal complications. ${ }^{18}$ Therefore, it is advised to discontinue lithium when the pregnancy is in the state of regular contractions (in partu), and re-instate lithium directly postdelivery. ${ }^{18,82}$ Since the floppy infant syndrome develops directly after birth and is dose related, it is clearly related to lithium toxicity (Table 1). However, symptoms can also occur in combination with low maternal or neonatal serum levels of lithium, ${ }^{62,83,86}$ suggesting that some infants are more vulnerable to develop symptoms of toxicity compared to others. Unfortunately, evidence is too limited to draw conclusions on the exact etiology. ${ }^{83}$

Since lithium is the mood stabiliser most prescribed during pregnancy ${ }^{83}$ other mood stabilisers are less frequently used and therefore also less frequently studied. After exposure to lamotrigine, PNA symptoms, such as decreased muscle tone and sedation, are described. ${ }^{58}$ The moment of onset and duration are not described.

Other commonly used mood stabilisers are valproic acid and carbamazepine. However, these drugs are not recommended during pregnancy since there is an elevated risk of malformations and long term complications after exposure to these drugs in utero.

\section{Benzodiazepines}

Benzodiazepines are frequently prescribed during pregnancy. Approximately $3 \%$ of all pregnant women uses this type of medication. ${ }^{12}$ After exposure to benzodiazepines during the last trimester of pregnancy, infants may develop symptoms of the floppy infant syndrome, as well as PNA, which can also merge into each other. ${ }^{19,43,54,58,60-62,88}$ Figures on the incidence of both syndromes are not available.

Factors which influence the development of neonatal symptoms include the pharmacokinetic properties of the benzodiazepine, degree of placental passage, duration of drug ingestion, dose, moment of last drug ingestion and metabolism and excretion by the infant. ${ }^{58,89}$ The floppy infant syndrome is most likely due to benzodiazepine toxicity. High medication dosages (equivalent of diazepam $>30 \mathrm{mg}$ ) in combination with benzodiazepines with a long half-life, such as nitrazepam and diazepam, give the highest risk, since this leads to accumulation in infants (Table 1). ${ }^{54,58,61,89}$ Benzodiazepines with a short half-life, such as oxazepam and temazepam, do not lead to toxicity in most cases. However, the risk of withdrawal is increased compared to benzodiazepines with a long halflife (Table 1). ${ }^{54,89}$ Symptoms of the floppy infant syndrome develop directly after birth and can persist for hours to days. Symptoms of PNA mostly develop within hours after birth and can persist for months..$^{54,62,89}$ Since the floppy infant syndrome can cause severe morbidity, prescription of benzodiazepines in the last trimester of pregnancy is not recommended.

\section{Influential factors}

Some infants develop symptoms of PNA while others do not. There is limited evidence on factors that create vulnerability to develop PNA. In the next section we will discuss existing literature on possible influencing factors of PNA.

\section{Prematurity}

One study described an increased risk of PNA in premature infants, arguing that these infants show more lung and central nervous system immaturity. ${ }^{42}$ Another study did not find this relationship. ${ }^{70}$ Some authors hypothesised that prematurity can also be protective for PNA, since this has also been observed in infants exposed to illicit drugs. ${ }^{23,32}$ 


\section{Intoxications}

Use of alcohol, nicotine and illicit drugs during pregnancy can also cause PNA. ${ }^{32,90}$ Based on our experience there is an increased risk of PNA after exposure to these substances in combination with psychotropic drugs. However, literature on the combination of respectively alcohol and illicit drugs with psychotropic drugs is lacking. Although smoking can lead to withdrawal symptoms, ${ }^{90}$ studies which examined the effect of smoking on PNA after exposure to psychotropic drugs concluded that smoking did not elevate the risk of PNA. ${ }^{42,70,91,92}$

\section{Exposure to multiple psychotropic drugs}

Only one study examined whether the risk of PNA increased after exposure to multiple psychotropic drugs. Infants exposed to paroxetine combined with clonazepam revealed more PNA symptoms compared to infants exposed to monotherapy of SSRIs during the last trimester of pregnancy. ${ }^{27}$ In conclusion, an association between the use of multiple psychotropic drugs and PNA is plausible. However, additional research is necessary in order to investigate this possible association.

\section{Dosage}

After exposure to lithium and benzodiazepines, a relation between maternal dosage and PNA symptoms has been described. ${ }^{18,27,93}$ Literature is inconclusive regarding SSRIs. ${ }^{17,26,27,39}$ However, an observational study in 247 infants exposed to SSRIs, mirtazapine or venlafaxine, performed by our research group, concluded that there was no relation between the risk of PNA and dosage.

One study investigated the relation between the plasma concentration of clomipramine and symptoms of PNA and showed a weak correlation. ${ }^{41}$ The relation between PNA and the dosage of other psychotropic drugs has not been published.

\section{Timing and duration of exposure}

One study described that infants exposed to SSRIs during the last two weeks of pregnancy have the same incidence of PNA compared to infants not exposed to SSRIs during this period. The authors postulate that some adverse neonatal outcomes may not be the result of an acute pharmacological condition such as toxicity or withdrawal. ${ }^{94}$ A second study by the same study group showed that in contrast to timing, duration of SSRI exposure was significantly correlated with poor neonatal outcomes. ${ }^{39}$

With regard to lithium, the timing of the last dosage does influence the perinatal outcome (as described earlier).

\section{Type of feeding}

A study of infants exposed to clomipramine did not reveal a relation between PNA and type of feeding. ${ }^{41}$ However, two studies in infants exposed to opioids in utero showed that breastfed infants developed less PNA compared to formula fed infants. ${ }^{95,96}$ The previously mentioned observational study of our research group concluded that breastfeeding is protective for PNA in 247 infants exposed to SSRIs, mirtazapine or venlafaxine in utero. This finding can be explained by the excretion of small amounts of psychotropic drugs into the breast milk, which might lead to a slower decrease and therefore to less symptoms of PNA. ${ }^{17,97}$ Another possible explanation is the increase of skin to skin contact during breastfeeding.

\section{Maternal psychiatric symptoms}

Depression or anxiety during and after pregnancy may lead to irritation, inconsolable crying and decreased activity in infants. ${ }^{7,8,36-39}$ Two studies examined the relation between the amount of depressive symptoms and PNA, though results were conflicting. ${ }^{70,91}$

\section{Genetic factors}

Regarding SSRIs, an interaction between genetic factors and environment probably influences the occurrence of PNA. ${ }^{27,48,52,98}$

Fluoxetine, paroxetine and sertraline are metabolised by CYP450 2D6. ${ }^{27}$ Therefore, in mothers with a deficiency of this cytochrome (also called poor metabolizers), plasma concentrations of these SSRIs are elevated which can increase the risk of toxicity in the infant. ${ }^{27,48}$

Furthermore, polymorphism in the promoter region of the serotonin transporter gene, SLC6A4, leads to differential gene expression, and consequent differences in clinical effects of SSRIs in adults and infants. ${ }^{48,98}$

\section{Observation of PNA}

In order to objectify possible symptoms of PNA, standardised observation of mother and child at the maternity ward is preferred. Admission at the Neonatal Care Unit (NCU) is not necessary since PNA is mostly mild and admission at the maternity ward enhances attachment between mother and child. Only when PNA symptoms are severe, such as severe tremors or convulsions, admittance to the NCU is warranted. ${ }^{23}$

If PNA symptoms do not occur, an observation period of 48-72 hours is sufficient. ${ }^{23,24,26,55,99}$ This applies to all types of psychotropic drugs. When PNA symptoms are present it 
is advisable to observe the infant until the PNA symptoms are fully resolved. ${ }^{100} \mathrm{~A}$ shorter observation period entails the risk of development of symptoms at home. Since the symptoms are nonspecific it is difficult to instruct parents. In addition, an infant with symptoms of restlessness with unknown origin can possibly provoke psychiatric symptoms, such as anxiety or depression in mothers with an existing psychiatric disorder.

\section{Scoring system}

To recognise, observe and objectify the development and progression of PNA, a scoring system is essential. ${ }^{37,101}$ At present there is no validated scoring system for observation of PNA in infants exposed to psychotropic drugs in utero. However, the Finnegan scoring list is widely used as an observation tool for PNA, although this list was originally designed to assess PNA after exposure to opiates. ${ }^{23,24,26,32,37,55,76,102}$ The list consists of 21 symptoms with a point scale ranging from 0 to 5 for each item. A score of 4-7 is indicative for mild symptoms of PNA and a score of 8 and above is considered to illustrate severe symptoms of PNA. Trained nurses administer the score every 8 hours. In case of a score of 8 or higher observation is increased to every 2 hours. ${ }^{24}$ To enhance reliability it is important that nurses and doctors are trained in administrating the Finnegan scoring list. Since some symptoms, such as loose stools, are not specific for PNA, the score can be elevated in absence of PNA. For this reason interpretation of the score has to be carried out by the pediatrician on daily basis. In cases where the Finnegan score is 8 or higher, the pediatrician should be consulted.

\section{Differential diagnosis and additional testing}

Since infants have a limited repertoire of nonspecific activities, it can be difficult to distinguish between PNA and other neonatal syndromes. The differential diagnosis of PNA consists of infection, metabolic or neurologic problems, hyper viscosity, and excitation syndromes, such as small for gestational age. $^{32,37,41}$ In case of debate on the origin of the presenting symptoms, these diagnoses have to be excluded. However, to prevent overmuch additional testing, it is important to observe infants by specialized caregivers in order to recognise PNA. ${ }^{17,22,24,32,37,42,69}$ The pediatrician evaluates the moment of onset of symptoms, the course and type of symptoms and examines the infant. When symptoms are present which are not typical for PNA, such as fever, or a nonspecific course of symptoms, such as symptoms that develop $>48$ hours postpartum, other diagnoses have to be excluded.
Alcohol or illicit drug use during pregnancy can also cause PNA. ${ }^{32}$ When there is any doubt on possible intoxications during pregnancy, toxicological urine screening is indicated. ${ }^{55}$

\section{Treatment}

Most cases of PNA are mild, of short duration and selflimiting, without need for treatment. ${ }^{5,19,22,24,26,42,46,69}$ Supporting measures, such as frequent small feedings on demand, swaddling and increase of skin to skin contact with mother, leading to an improved temperature regulation, and more regular breathing, is mostly sufficient. $5,19,24,26,37,42,46,69$ When there is severe PNA and supporting measures are not sufficient, phenobarital is a safe, therapeutic option. ${ }^{22-24}$ This symptomatic treatment is also used in cases of opiate withdrawal. ${ }^{22-24}$ Although there are no studies on

Table 3 Recommendations regarding observation and treatment of Poor Neonatal Adaptation (PNA)

\section{General recommendations}

In otherwise healthy infants routine additional laboratory tests in order to exclude possible neonatal complications are not required. Observation at the maternity ward is preferred. Only when PNA symptoms are severe, admittance to the Neonatal Care Unit is necessary.

Discourage the use of illicit drugs and alcohol since these substances also cause PNA.

An observation period of $48-72$ hours is sufficient when no PNA symptoms occur.

When PNA symptoms are present observe the infant until the PNA symptoms are fully resolved.

The Finnegan scoring list has to be administered every 8 hours by trained nurses.

In case of a score of 8 or higher this has to be intensified to every 2 hours. Interpretation of the score has to be carried out by the pediatrician. In case of debate on the origin of presenting symptoms other diagnoses such as infection, metabolic or neurologic problems, hyper viscosity, and excitation syndromes like small for gestational age have to be excluded.

In case of any doubt on possible intoxications during pregnancy toxicological urine screening is indicated.

Supporting measures such as frequent small feedings on demand, swaddling and increase of skin to skin contact with mother is mostly sufficient.

When there is severe PNA and supporting measures are not sufficient, phenobarital is a safe therapeutic option. When using the Finnegan scoring list $\geq 2$ scores of 8 or higher in between 2 hours is an indication of pharmacotherapy.

\section{Drug specific recommendations}

After exposure to lithium during pregnancy, discontinue when the patient is in partu and re-instate directly post delivery.

The dosage of antidepressants seems not related to the risk of development of PNA. Therefore, lowering the dosage is not useful in order to prevent PNA.

Encourage breastfeeding after exposure to SSRIs, mirtazapine or venlafaxine, since this probably reduces the risk of PNA. 
the efficacy of phenobarbital in this application, efficacy in infants with irritation or convulsions is established and safe. ${ }^{103}$ When the Finnegan scoring list is used $\geq 2$ scores of 8 or higher within a 2 hour period is an indication of pharmacotherapy at the NCU. ${ }^{24}$

Many parents have feelings of guilt when symptoms of PNA are present. ${ }^{37}$ It is important to be clear about the diagnosis on one hand, and explain the transitory, self-limiting course of the symptoms on the other. ${ }^{26,27}$ Table 3 presents recommendations regarding the observation and treatment of PNA.

\section{Long term effects of PNA}

The effect of PNA on the neurological development in children of 2-6 years is studied by Klinger. ${ }^{104}$ In this study 30 infants with PNA, and 52 infants without PNA, all exposed to SSRIs, were followed. There was no significant difference in IQ, findings during neurological examination and total development score ${ }^{104}$ (measured by the Denver development test). The subscale 'social behaviour' was significantly lower in infants with PNA postpartum. ${ }^{104}$ Oberlander assessed the development in children of 2 and 8 months exposed to SSRI and clonazepam and noted no significant differences between infants with and without PNA. ${ }^{27}$ Additional research is necessary to examine the long terms effects of PNA.

\section{Conclusion}

After exposure to psychotropic drugs in utero infants are at risk to develop symptoms of PNA. Although there is debate on the exact etiology of PNA the most plausible explanation is withdrawal, toxicity, or a combination of both. Distinguishing PNA of toxicity is difficult since symptoms of PNA and toxicity are largely similar.

PNA consists of neurologic, autonomic, respirator and gastro-intestinal symptoms, which are largely similar after exposure of antidepressants, antipsychotics and benzodiazepines. In most infants symptoms are mild, such as sleep disturbances. Severe symptoms, such as convulsions, are rare. Of all infants exposed to antidepressants in utero, around $20 \%-50 \%$ develop symptoms of PNA. Figures on the incidence of PNA after exposure to antipsychotic drugs, mood stabilizers or benzodiazepines are lacking. Most symptoms of PNA develop within 48 hours and last for 2-6 days. However, after exposure to benzodiazepines, symptoms can persist for months. If symptoms do not occur in the first 48 hours, development of PNA is unlikely.
Influential factors of PNA are scarcely studied. There is conflicting evidence regarding the effect of prematurity and maternal psychiatric symptoms on PNA. After exposure to SSRIs, mirtazapine or venlafaxine in utero, breastfeeding is presumed to be protective for development of PNA. Furthermore, the dosage of antidepressants seems not to be related to the risk of PNA. Therefore, lowering the dosage of antidepressants is not useful in order to prevent PNA. This does not apply for benzodiazepines and lithium.

Observation on the maternity ward is preferred, since PNA is mostly mild and admission at the maternity ward enhances attachment between mother and child. Only when PNA symptoms are severe is admittance to the NCU necessary. If PNA symptoms do not occur, an observation period of 48-72 hours is sufficient. This applies to all types of psychotropic drugs. When PNA symptoms are present it is advisable to observe the infant until the PNA symptoms are fully resolved.

To observe and objectify the development and progression of PNA a scoring system is essential. The Finnegan scoring list has to be administered every 8 hours by trained nurses. In case of a score of 8 or higher this has to be intensified to every 2 hours. Since the Finnegan scoring list lacks specificity, interpretation of the score should be carried out by a pediatrician.

Since infants have a limited repertoire of nonspecific activities, it can be difficult to differentiate between PNA and other neonatal syndromes. The differential diagnosis of PNA consists of infection, metabolic of neurologic problems, hyper viscosity, and excitation syndromes such as small for gestational age. In case of debate on the origin of presenting symptoms these diagnoses have to be excluded. When there is any doubt on possible intoxications during pregnancy, toxicological urine screening is indicated.

Most cases of PNA are mild, of short duration and selflimiting without need for treatment. Supporting measures such as frequent, small feedings on demand, swaddling and increased skin to skin contact with mother, leading to an improved temperature regulation and a more regular breathing, is usually sufficient. When there is severe PNA and supporting measures are not sufficient, phenobarital is a safe therapeutic option. When using the Finnegan scoring list $\geq 2$ scores of 8 or higher within 2 hours is an indication of pharmacotherapy.

Long term effects of PNA are examined in two studies. ${ }^{27,104}$ There seem to be no major effects; however, additional 
studies are necessary in order to draw any conclusions on this matter.

\section{Disclosure}

The authors declare no conflicts of interest in this work. No external funding was secured for this study.

\section{References}

1. Marcus SM, Flynn HA, Blow FC, Barry KL. Depressive symptoms among pregnant women screened in obstetrics settings. JWomens Health (Larchmt). 2003;12(4):373-380. doi:10.1089/154099903765448880

2. Andersson L, Sundstromporomaa L, Bixo M, Wuff M, Bondestam K, Astrom M. Point prevalence of psychiatric disorders during the second trimester of pregnancy: A population-based study. American Journal of Obstetrics and Gynecology. 2003;189(1):148-154. doi:10.1067/ mob.2003.336

3. Goedhart G, Snijders AC, Hesselink AE, van Poppel MN, Bonsel GJ, Vrijkotte TGM. Maternal Depressive Symptoms in Relation to Perinatal Mortality and Morbidity: Results From a Large Multiethnic Cohort Study. Psychosomatic Medicine. 2010;72(8):769-776. doi:10.1097/ PSY.0b013e3181ee4a62

4. Lee H-C, Lin H-C. Maternal bipolar disorder increased low birthweight and preterm births: A nationwide population-based study. Journal of Affective Disorders. 2010;121(1-2):100-105. doi:10.1016/j. jad.2009.05.019

5. Oberlander TF, Warburton W, Misri S, Aghajanian J, Hertzman C. Neonatal outcomes after prenatal exposure to selective serotonin reuptake inhibitor antidepressants and maternal depression using population-based linked health data. Arch Gen Psychiatry. 2006;63(8):898-906. doi:10.1001/archpsyc.63.8.898

6. Field T, Diego M, Hernandez-Reif M. Prenatal depression effects and interventions: A review. Infant Behavior and Development. 2010;33(4):409-418. doi:10.1016/j.infbeh.2010.04.005

7. Zuckerman B, Bauchner H, Parker S, Cabral H. Maternal depressive symptoms during pregnancy, and newborn irritability. J Dev Behav Pediatr. 1990;11(4):190-194.

8. Lundy B. Prenatal depression effects on neonates. Infant Behavior and Development. 1999;22(1):119-129. doi:10.1016/S0163-S6383(99) 80009-5.

9. Hay DF, Pawlby S, Waters CS, Sharp D. Antepartum and postpartum exposure to maternal depression: different effects on different adolescent outcomes. Journal of Child Psychology and Psychiatry. 2008;49(10):1079-1088. doi:10.1111/j.1469-7610.2008.01959.x

10. Wan MW, Salmon MP, Riordan DM, Appleby L, Webb R, Abel KM. What predicts poor mother-infant interaction in schizophrenia? Psychol. Med. 2006;37(04):537. doi:10.1017/S0033291706009172

11. Murray L, Fiori-Cowley A, Hooper R, Cooper P. The impact of postnatal depression and associated adversity on early mother-infant interactions and later infant outcome. Child Dev. 1996;67(5):2512-2526.

12. Bellantuono C, Bozzi F, Orsolini L, Catena-Dell'Osso M. The safety of escitalopram during pregnancy and breastfeeding: a comprehensive review. Hum Psychopharmacol. 2012;27(6):534-539. doi:10.1002/hup.2265

13. Yonkers KA, Wisner KL, Stewart DE, et al. The management of depression during pregnancy: a report from the American Psychiatric Association and the American College of Obstetricians

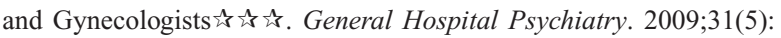
403-413. doi:10.1016/j.genhosppsych.2009.04.003.

14. NICE. Antenatal and postnatal mental health. National Institute for Clinical Excellence. 2007:1-51.

15. Bellantuono C, Migliarese G, Gentile S. Serotonin reuptake inhibitors in pregnancy and the risk of major malformations: a systematic review. Hum Psychopharmacol. 2007;22(3):121-128. doi:10.1002/hup.836.

16. Haddad P. Antidepressant discontinuation syndromes: clinical relevance, prevention and management. Drug Safety. 2001;24(3):183-197.
17. Galbally M, Lewis AJ, Lum J, Buist A. Serotonin discontinuation syndrome following in utero exposure to antidepressant medication: prospective controlled study. Aust N Z J Psychiatry. 2009;43(9): 846-854. doi:10.1080/00048670903107583

18. Newport DJ, Viguera AC, Beach AJ, Ritchie JC, Cohen LS, Stowe ZN. Lithium placental passage and obstetrical outcome: implications for clinical management during late pregnancy. Am J Psychiatry. 2005;162(11):2162-2170. doi:10.1176/appi.ajp.162.11.2162

19. Altshuler LL, Cohen L, Szuba MP, Burt VK, Gitlin M, Mintz J. Pharmacologic management of psychiatric illness during pregnancy: dilemmas and guidelines. Am J Psychiatry. 1996;153(5):592-606.

20. Rampono J, Simmer K, Ilett KF, et al. Placental Transfer of SSRI and SNRI Antidepressants and Effects on the Neonate. Pharmacopsychiatry. 2009;42(03):95-100. doi:10.1055/s-0028-1103296

21. Boucher N, Bairam A, Beaulac-Baillargeon L. A new look at the neonate's clinical presentation after in utero exposure to antidepressants in late pregnancy. Journal of Clinical Psychopharmacology. 2008;28(3):334-339. doi:10.1097/JCP.0b013e318173aa2e

22. Koren G. Is maternal use of selective serotonin reuptake inhibitors in the third trimester of pregnancy harmful to neonates? Canadian Medical Association Journal. 2005;172(11):1457-1459. doi:10.1503/ cmaj. 1041100

23. Klinger G, Merlob P. Selective serotonin reuptake inhibitor induced neonatal abstinence syndrome. Isr J Psychiatry Relat Sci. 2008;45(2): 107-113.

24. Sie SD, Wennink JMB, van Driel JJ, et al. Maternal use of SSRIs, SNRIs and NaSSAs: practical recommendations during pregnancy and lactation. Archives of Disease in Childhood - Fetal and Neonatal Edition. 2012;97(6):F472-F476. doi:10.1136/archdischild-2011-214239.

25. Anbu AT, Theodore A. Fluoxetine withdrawal syndrome in the newborn. Indian Pediatr. 2006;43(1):66-69.

26. Levinson-Castiel R, Merlob P, Linder N, Sirota L, Klinger G. Neonatal abstinence syndrome after in utero exposure to selective serotonin reuptake inhibitors in term infants. Arch Pediatr Adolesc Med. 2006;160(2):173-176. doi:10.1001/archpedi.160.2.173

27. Oberlander TF, Misri S, Fitzgerald CE, Kostaras X, Rurak D, Riggs W. Pharmacologic factors associated with transient neonatal symptoms following prenatal psychotropic medication exposure. J Clin Psychiatry. 2004;65(2):230-237.

28. Laine K, Heikkinen T, Ekblad U, Kero P. Effects of exposure to selective serotonin reuptake inhibitors during pregnancy on serotonergic symptoms in newborns and cord blood monoamine and prolactin concentrations. Arch Gen Psychiatry. 2003;60(7):720-726. doi:10.1001/archpsyc.60.7.720

29. Isbister GK, Dawson A, Whyte IM, Prior FH, Clancy C, Smith AJ. Neonatal paroxetine withdrawal syndrome or actually serotonin syndrome? Archives of Disease in Childhood - Fetal and Neonatal Edition. 2001;85(2):F147-F148.

30. Knoppert DC, Nimkar R, Principi T, Yuen D. Paroxetine toxicity in a newborn after in utero exposure: clinical symptoms correlate with serum levels. In: 2006;28:5-7.

31. Stiskal JA. Defective alleles may not have contributed to adverse effects. Ther Drug Monit. 2006;28(1):142-author reply 143.

32. Hudak ML, Tan RC. Newborn COFA, American Academy of Pediatrics, Newcomb C, drugs CO. Neonatal drug withdrawal. PEDIATRICS. 2012;129(2):e540-e560. doi:10.1542/peds.2011-3212

33. Bellissima V, Ververs TFF, Visser GHA, Gazzolo D. Selective serotonin reuptake inhibitors in pregnancy. Curr Med Chem. 2012;19(27): 4554-4561.

34. Sanz EJ, De-las-Cuevas C, Kiuru A, Bate A, Edwards R. Selective serotonin reuptake inhibitors in pregnant women and neonatal withdrawal syndrome: a database analysis. Lancet. 2005;365(9458):482-487. doi:10.1016/S0140-6736(05)17865-9

35. Gentile S. On categorizing gestational, birth, and neonatal complications following late pregnancy exposure to antidepressants: the prenatal antidepressant exposure syndrome. CNS Spectr. 2010;15(3): $167-185$. 
36. Byatt N, Deligiannidis KM, Freeman MP. Antidepressant use in pregnancy: a critical review focused on risks and controversies. Acta Psychiatrica Scandinavica. 2013;127(2):94-114. doi:10.1111/acps.12042

37. Jansson LM, Velez M. Neonatal abstinence syndrome. Curr Opin Pediatr. 2012;24(2):252-258. doi:10.1097/MOP.0b013e32834fdc3a

38. FieldT. Prenatal Depression and Selective Serotonin Reuptake Inhibitors. Int J Neurosci. 2010;120(3):163-167. doi:10.3109/00207450802338697

39. Oberlander TF, Warburton W, Misri S, Aghajanian J, Hertzman C. Effects of timing and duration of gestational exposure to serotonin reuptake inhibitor antidepressants: population-based study. The British Journal of Psychiatry. 2008;192(5):338-343. doi:10.1192/bjp.bp.107.037101

40. Zeskind PS, Stephens LE. Maternal Selective Serotonin Reuptake Inhibitor Use During Pregnancy and Newborn Neurobehavior. PEDIATRICS. 2004;113(2):368-375. doi:10.1542/peds.113.2.368

41. Horst Ter PGJ, van der Linde S, Smit JP, et al. Clomipramine concentration and withdrawal symptoms in ten neonates. $\mathrm{Br} \mathrm{J}$ Clin Pharmacol. 2011:1-8. doi:10.1111/j.1365-2125.2011.04072.x

42. Ferreira E, Carceller AM, Agogue C, et al. Effects of Selective Serotonin Reuptake Inhibitors and Venlafaxine During Pregnancy in Term and Preterm Neonates. PEDIATRICS. 2007;119(1):52-59. doi:10.1542/ peds.2006-2133

43. Uzun S, Kozumplik O, Jakovljević M, Sedić B. Side effects of treatment with benzodiazepines. Psychiatr Danub. 2010;22(1):90-93.

44. Galbally M, Snellen M, Walker S, Permezel M. Management of antipsychotic and mood stabilizer medication in pregnancy: recommendations for antenatal care. Aust $N Z$ J Psychiatry. 2010;44(2):99-108. doi:10.3109/00048670903487217

45. Scheffers TPH, Enk JG. Gevolgen ssri-gebruik zwangeren bij de pasgeborene in de eerste 48 uur post partum. [Neonatal effects of SSRI-use during pregnancy during the first 48 hours after birth]. KIND. 2007;75(4):159-164. doi:10.1007/BF03061685

46. Udechuku A, Nguyen T, Hill R, Szego K. Antidepressants in pregnancy: a systematic review. Aust $N Z$ J Psychiatry. 2010;44(11):978-996. doi:10.3109/00048674.2010.507543

47. Chambers CD, Johnson KA, Dick LM, Felix RJ, Jones KL. Birth outcomes in pregnant women taking fluoxetine. $N \mathrm{Engl} \mathrm{J} \mathrm{Med}$. 1996;335(14):1010-1015. doi:10.1056/NEJM199610033351402

48. Alwan S, Friedman JM. Safety of selective serotonin reuptake inhibitors in pregnancy. CNS Drugs. 2009;23(6):493-509. doi:10.2165/00023210200923060-00004

49. Källén B, Olausson PO. Maternal use of selective serotonin re-uptake inhibitors and persistent pulmonary hypertension of the newborn. Pharmacoepidem Drug Safe. 2008;17(8):801-806. doi:10.1002/pds.1570

50. Coppola D, Russo LJ, Kwarta RF, Varughese R, Schmider J. Evaluating the postmarketing experience of risperidone use during pregnancy: pregnancy and neonatal outcomes. Drug Saf. 2007;30(3):247-264.

51. Grzeskowiak LE, Gilbert AL, Morrison JL. Investigating outcomes following the use of selective serotonin reuptake inhibitors for treating depression in pregnancy: a focus on methodological issues. Drug Saf. 2011;34(11):1027-1048. doi:10.2165/11593130000000000-00000

52. Malm H. Prenatal exposure to selective serotonin reuptake inhibitors and infant outcome. Ther Drug Monit. 2012;34(6):607-614. doi:10.1097/ FTD.0b013e31826d07ea

53. Kendall-Tackett K, Hale TW. The use of antidepressants in pregnant and breastfeeding women: a review of recent studies. J Hum Lact. 2010;26(2):187-195. doi:10.1177/0890334409342071

54. McElhatton PR. The effects of benzodiazepine use during pregnancy and lactation. Reprod Toxicol. 1994;8(6):461-475.

55. Koren G, Finkelstein Y, Matsui D, Berkovich M. Diagnosis and management of poor neonatal adaptation syndrome in newborns exposed in utero to selective seretonin/norepinephrine reuptake inhibitors. J Obstet Gynaecol Can. 2009;31(4):348-350.

56. Lattimore KA, Donn SM, Kaciroti N, Kemper AR, Neal CR, Vazquez DM. Selective Serotonin Reuptake Inhibitor (SSRI) Use during Pregnancy and Effects on the Fetus and Newborn: A Meta-Analysis. J Perinatol. 2005;25(9):595-604. doi:10.1038/sj.jp.7211352
57. Oyebode F, Rastogi A, Berrisford G, Coccia F. Psychotropics in pregnancy: safety and other considerations. Pharmacol Ther. 2012;135(1):71-77. doi:10.1016/j.pharmthera.2012.03.008

58. Krüger S. Psychopharmacological Treatment of Mood and Anxiety Disorders During Pregnancy. In: Handbook of Experimental Pharmacology. Handbook of Experimental Pharmacology. Berlin, Heidelberg: Springer Berlin Heidelberg; 2012;214:279-305. doi:10.1007/978-3-642-30726-3_14.

59. Gentile S. Drug treatment for mood disorders in pregnancy. Curr Opin Psychiatry. 2011;24(1):34-40. doi:10.1097/YCO.0b013e3283413451

60. Hauser LA. Pregnancy and psychiatric drugs. Hosp Community Psychiatry. 1985;36(8):817-818.

61. Miller LJ. Psychopharmacology during pregnancy. Prim Care Update Ob/Gyn. 1996;3(3):79-85.

62. Sitland-Marken PA, Rickman LA, Wells BG, Mabie WC. Pharmacologic management of acute mania in pregnancy. Journal of Clinical Psychopharmacology. 1989;9(2):78-87.

63. Levy M, Spino M. Neonatal withdrawal syndrome: associated drugs and pharmacologic management. Pharmacotherapy. 1993;13(3): 202-211.

64. Patil AS, Kuller JA, Rhee EHJ. Antidepressants in pregnancy: a review of commonly prescribed medications. Obstet Gynecol Surv. 2011;66(12):777-787. doi:10.1097/OGX.0b013e31823e0cbf

65. Bakker MK, Kölling P, van den Berg PB, de Walle HEK, de Jong-van den Berg LTW. Increase in use of selective serotonin reuptake inhibitors in pregnancy during the last decade, a population-based cohort study from the Netherlands. Br J Clin Pharmacol. 2008;65(4):600-606. doi:10.1111/j.1365-2125.2007.03048.x

66. Reefhuis J, Friedman J. Selective serotinin-reuptake inhibitors and persistent pulmonary hypertension of the newborn. N England Journal of Medicine. 2006;354:2188-2189.

67. Ververs T, van Dijk L, Yousofi S, Schobben F, Visser GH. Depression during pregnancy: views on antidepressant use and information sources of general practitioners and pharmacists. BMC Health Serv Res. 2009;9(1):119. doi:10.1186/1472-6963-9-119

68. Seligman NS, Almario CV, Hayes EJ, Dysart KC, Berghella V, Baxter JK. Relationship between maternal methadone dose at delivery and neonatal abstinence syndrome. J Pediatr. 2010;157(3):428-433. e1. doi:10.1016/j.jpeds.2010.03.033

69. Moses-Kolko EL, Bogen D, Perel J, et al. Neonatal signs after late in utero exposure to serotonin reuptake inhibitors: literature review and implications for clinical applications. JAMA. 2005;293(19):2372-2383. doi:10.1001/jama.293.19.2372

70. Misri S, Oberlander TF, Fairbrother N, et al. Relation between prenatal maternal mood and anxiety and neonatal health. Can J Psychiatry. 2004;49(10):684-689.

71. Trenque T, Piednoir D, Frances C, Millart H, Germain ML. Reports of withdrawal syndrome with the use of SSRIs: a case/non-case study in the French Pharmacovigilance database. Pharmacoepidem Drug Safe. 2002;11(4):281-283. doi:10.1002/pds.704

72. Källén B. Neonate characteristics after maternal use of antidepressants in late pregnancy. Arch Pediatr Adolesc Med. 2004;158(4):312-316. doi:10.1001/archpedi.158.4.312

73. van Driel JJ, Wennink JHMB, Heres MHB, Honig A. Intrauterine exposure to SSRIs: no reason for routine hypoglycaemia screening. Ned Tijdschr Geneeskd. 2010;154(8):A339.

74. 't Jong GW, Einarson T, Koren G, Einarson A. Antidepressant use in pregnancy and persistent pulmonary hypertension of the newborn (PPHN): a systematic review. Reprod Toxicol. 2012;34(3):293-297. doi:10.1016/j.reprotox.2012.04.015

75. Food and Drug Administration advise on drug safety. Available from: http://www.fda.gov/Drugs/DrugSafety/ucm283375.htm. Accessed May 24, 2013.

76. Horst Ter PGJ, Jansman FGA, van Lingen RA, Smit J-P, de Jong-van den Berg LTW, Brouwers JRBJ. Pharmacological aspects of neonatal antidepressant withdrawal. Obstet Gynecol Surv. 2008;63(4):267-279. doi:10.1097/OGX.0b013e3181676be8 
77. Stewart DE. Clinical practice. Depression during pregnancy. $N$ Engl J Med. 2011;365(17):1605-1611. doi:10.1056/NEJMcp1102730

78. Gentile $\mathrm{S}$. The safety of newer antidepressants in pregnancy and breastfeeding. Drug Saf. 2005;28(2):137-152.

79. Boucher N, Koren G, Beaulac-Baillargeon L. Maternal use of venlafaxine near term: correlation between neonatal effects and plasma concentrations. Ther Drug Monit. 2009;31(3):404-409. doi:10.1097/ FTD.0b013e3181a58fb4

80. Nielsen RE, Damkier P. Pharmacological treatment of unipolar depression during pregnancy and breast-feeding - a clinical overview. Nord J Psychiatry. 2012;66(3):159-166. doi:10.3109/08039488. 2011.650198

81. Newport DJ, Calamaras MR, DeVane CL, et al. Atypical antipsychotic administration during late pregnancy: placental passage and obstetrical outcomes. Am J Psychiatry. 2007;164(8):1214-1220. doi:10.1176/appi. ajp.2007.06111886

82. Galbally M, Snellen M, Lewis AJ. A review of the use of psychotropic medication in pregnancy. Curr Opin Obstet Gynecol. 2011;23(6): 408-414. doi:10.1097/GCO.0b013e32834b92f3

83. Gentile S. Lithium in pregnancy: the need to treat, the duty to ensure safety. Expert Opin Drug Saf. 2012;11(3):425-437. doi:10.1517/1474 0338.2012.670419

84. Galbally M, Roberts M, Buist A. Perinatal Psychotropic Review Group. Mood stabilizers in pregnancy: a systematic review. Aust N Z J Psychiatry. 2010;44(11):967-977. doi:10.3109/00048674.2010.50 6637

85. Iqbal MM, Sohhan T, Mahmud SZ. The effects of lithium, valproic acid, and carbamazepine during pregnancy and lactation. $J$ Toxicol Clin Toxicol. 2001;39(4):381-392.

86. Ananth J. Side effects on fetus and infant of psychotropic drug use during pregnancy. Int Pharmacopsychiatry. 1976;11(4):246-260.

87. Kozma C. Neonatal toxicity and transient neurodevelopmental deficits following prenatal exposure to lithium: Another clinical report and a review of the literature. Am J Med Genet. 2005;132A(4):441-444. doi:10.1002/ajmg.a.30501

88. Robinson GE, Stewart DE, Flak E. The rational use of psychotropic drugs in pregnancy and postpartum. Can J Psychiatry. 1986;31(3): 183-190.

89. Kanto J, Erkkola R. Obstetric analgesia: pharmacokinetics and its relation to neonatal behavioral and adaptive functions. Biol Res Pregnancy Perinatol. 1984;5(1):23-35.

90. García-Algar O. Nicotine withdrawal symptoms in newborns. Arch Bronconeumol. 2008;44(10):509-511.

91. Sit D, Perel JM, Wisniewski SR, Helsel JC, Luther JF, Wisner KL. Mother-Infant Antidepressant Concentrations, Maternal Depression, and Perinatal Events. J Clin Psychiatry. 2011;72(07):994-1001. doi:10.4088/JCP.10 m06461
92. Costei AM, Kozer E, Ho T, Ito S, Koren G. Perinatal outcome following third trimester exposure to paroxetine. Arch Pediatr Adolesc Med. 2002;156(11):1129-1132.

93. Whitelaw AG, Cummings AJ, McFadyen IR. Effect of maternal lorazepam on the neonate. Br Med J (Clin Res Ed). 1981;282(6270): 1106-1108.

94. Warburton W, Hertzman C, Oberlander TF. A register study of the impact of stopping third trimester selective serotonin reuptake inhibitor exposure on neonatal health. Acta Psychiatrica Scandinavica. 2009;121(6):471-479. doi:10.1111/j.1600-0447.2009.01490.x

95. Abdel-Latif ME. Effects of Breast Milk on the Severity and Outcome of Neonatal Abstinence Syndrome Among Infants of Drug-Dependent Mothers. PEDIATRICS. 2006;117(6):e1163-e1169. doi:10.1542/ peds.2005-1561

96. McQueen KA, Murphy-Oikonen J, Gerlach K, Montelpare W. The impact of infant feeding method on neonatal abstinence scores of methadone-exposed infants. Adv Neonatal Care. 2011;11(4):282-290. doi:10.1097/ANC.0b013e318225a30c

97. Koren G, Moretti M, Kapur B. Can venlafaxine in breast milk attenuate the norepinephrine and serotonin reuptake neonatal withdrawal syndrome. J Obstet Gynaecol Can. 2006;28(4):299-302.

98. Oberlander TF, Bonaguro RJ, Misri S, Papsdorf M, Ross CJD, Simpson EM. Infant serotonin transporter (SLC6A4) promoter genotype is associated with adverse neonatal outcomes after prenatal exposure to serotonin reuptake inhibitor medications. Mol Psychiatry. 2007;13(1):65-73. doi:10.1038/sj.mp.4002007

99. Bot P. Neonatal effects of exposure to selective serotonin reuptake inhibitors during pregnancy. Archives of Disease in Childhood Fetal and Neonatal Edition. 2006;91(2):F153-F153. doi:10.1136/ adc.2004.066431

100. Kieviet N, Dolman K, Wennink H, Heres M, Honig A. Withdrawal in newborns after exposure to psychotropic medications during pregnancy. Ned Tijdschr Geneeskd. 2012;156(16):A4395.

101. Austin M-P. To treat or not to treat: maternal depression, SSRI use in pregnancy and adverse neonatal effects. Psychol Med. 2006;36(12):1663. doi:10.1017/S003329170600835X

102. Finnegan LP, Kron RE, Connaughton JF, Emich JP. Assessment and treatment of abstinence in the infant of the drug-dependent mother. Int J Clin Pharmacol Biopharm. 1975;12(1-2):19-32.

103. Vento M, de Vries LS, Alberola A, et al. Approach to seizures in the neonatal period: a European perspective. Acta Paediatrica. 2010;99(4):497-501. doi:10.1111/j.1651-2227.2009.01659.x

104. Klinger G, Frankenthal D, Merlob P, et al. Long-term outcome following selective serotonin reuptake inhibitor induced neonatal abstinence syndrome. J Perinatol. 2011. doi:10.1038/jp.2010.211
Neuropsychiatric Disease and Treatment

\section{Publish your work in this journal}

Neuropsychiatric Disease and Treatment is an international, peerreviewed journal of clinical therapeutics and pharmacology focusing on concise rapid reporting of clinical or pre-clinical studies on a range of neuropsychiatric and neurological disorders. This journal is indexed on PubMed Central, the 'PsycINFO' database and CAS.
Dovepress

The manuscript management system is completely online and includes a very quick and fair peer-review system, which is all easy to use. Visit $\mathrm{http}: / / \mathrm{www}$.dovepress.com/testimonials.php to read real quotes from published authors. 